\title{
فاوست بين غوته وباكثير
}

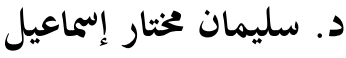

\section{كلية الآداب - جامعة مصراته}

تندرج هذه الدراسة ضمن درس الأدب المقارن، و هو أدب إنساني عالمي دولي يوثق

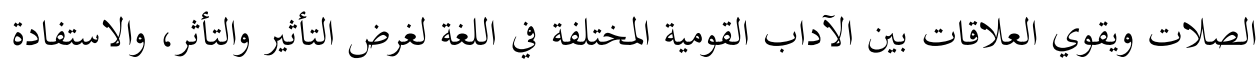
من الآداب العالمية والعودة للأدب القومي لتلقيحه وتطعيمه بالمذاهب والأجناس الأدبية والتيارات الفكرية، والقوالب الفنية؛ ليزدهر الأدب القومي ويتطور ويلحق بالآداب العالمية والإنسانية الحية المتطورة، ولا يمكن لموضوع ما أن ينمو ويتطور من دون مقارنة بما يماثله من لئن

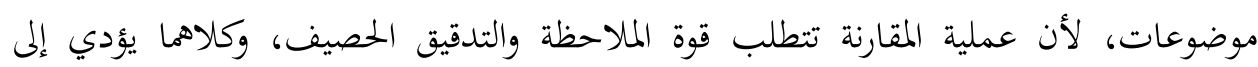
استنتاجات واكتشافات جديدة. وقد عُرّف الأدب المقارن بعدة تعريفات منها أنه: (( العلم الذي يُدرس على نحو

خاص آثار الآداب المختلفة في علاقاتحا المتبادلة ()) (1). وكان (فان تيجيم) أول من قدم تعريفا للأدب المقارن في كتابه الموجز عنه، الذي الذي صدرت طبعته الأولى في باريس سنة 1931م، يقول في تعريفه له: (( إنه العلم الذي يدرس على نخو خاص آثار الآداب المختلفة في علاقاتها المتبادلة ()(2). وعرفه (هنري رماك) في كتابه "الأدب المقارن المادة والمنهج (( بأنه دراسة الأدب فيما وراء حدود إقليم معين، ودراسة العلاقات بين الأدب ونواحي المعرفة الأخرى، بما فيها الفنون الجميلة، والفلسفة، والتاريخ، والعلوم الاجتماعية، والعلوم التجريبية، والأديان وغيرها )( (3).

1- الأدب المقارن أصوله وتطوره ومناهجه، الطاهر أحمد مكي، دار المعارف، القاهرة، الطبعة الأولى، 3- 1407 1407- المرجع السابق، صـ الادبع ص ص 1987. 
والمراد بالمقارنة: هي تقريب الأحداث المقتبسة من جماعات مختلفة، وبعيدة غالبا، لتستخرج منها قواعد عامة(1) فالدراسات المقارنة في -حقيقتها- وسيلة من وسائل التأثير والتأثر المتبادلين بين الأعمال الأدبية، والتاريخ للحركة الفنية في إطار أسثمل وأوسع هو إطار العالمية) والناتر

إن الأدب المقارن فرع من الأدب العام، وإن ثمة اختلاف بين المدرستين الفرنسية والأمريكية في تحديد موضوعه، يقول أصحاب المدرسة الفرنسية: إن الأدب المقارن يدرس مواطن التلاقي بين آداب اللغات المختلفة وصلاتما الكثيرة المعقدة في حاضرها وماضيها وما لهذه الصلات من تأثير وتأثر أيا كانت مظاهر هذا التأثير والتأثر، سواء أتعلقت بالأصول الفنية العامة للأجناس الأدبية، أو التيارات الفكرية، أو اتصلت بطبيعة الموضوع والمواقف والأشخاص

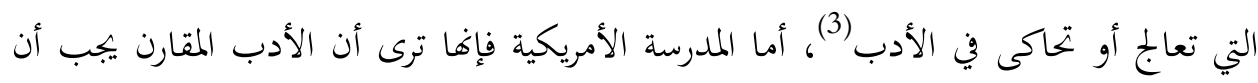
يشمل ما سبق ويذهب إلى أبعد منه، فيدرس وجوه الشبه والاختلاف بين أدبين أو أكثر. إن دراسة الأدب المقارن تعلمنا أن كل أدب يفرض على نفسه حدودا وطنية إنما يشوه

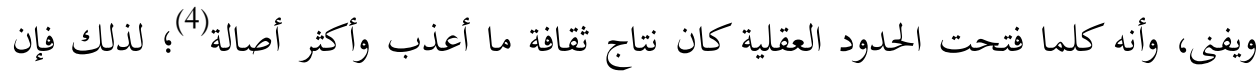
الأدب المقارن يهدف وإلى الانفتاح على الآداب الأخرى لتكوين أدب إنساني عام يستفيد منه البشر جميعا وتتكامل فيه اللغات والثقافات والتصورات والأفكار.

1- الأدب المقارن، ب، فان تيجيم، تعريب سالم مفتاح الحسامي، منشورات المكتبة العصرية، صيدا - بيروت، ص19.

$$
\text { 2- في الأدب المقارن، إبراهيم عبد الرحمن، مصر الجديدة، 1977م، ص10. }
$$

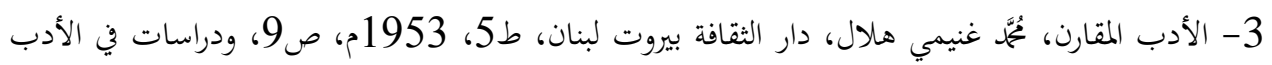

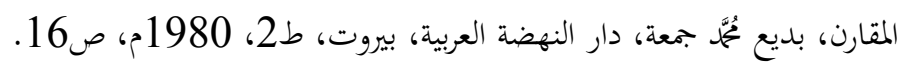

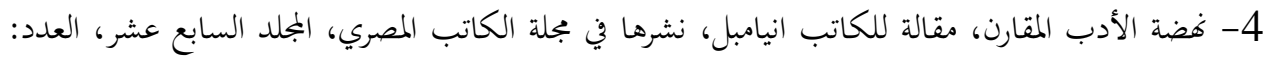

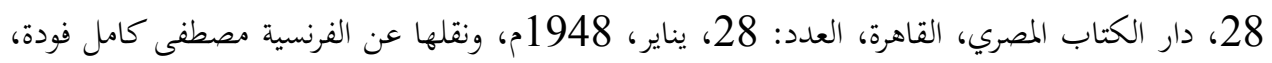


وفي هذه الدراسة أود أن أنظر إلى أسطورة (فاوست) من زاوية الأدب المقارن لنتبين

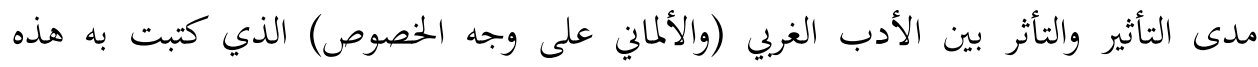

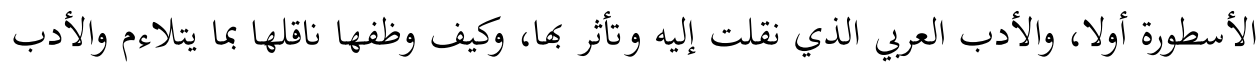
المنقولة إليه. وقبل أن أعرض لما بين (فاوست) عند (غوته)، و(فاوست) الجديد عند (علي أحمد باكثير) من علاقة يجدر بي أن أشير إلى أسطورة (فاوست) والمراحل التي مرت بها ثم أقف عند وأند التعريف ب(غوته) والتعريف بعلي أحمد باكثير، تثم عند عمليهما في (فاوست) وما بينهما من تقارب واختلاف.

\section{(فاوست)}

مما يتداوله الدارسون والنقاد عند حديثهم عن (فاوست) قولهم: "وإذا سأل سائل ما هي أعظم عشرة كتب في عالم الأدب منذ فجر الإنسانية إلى اليوم لكانت الإجابة" (فاوست)"

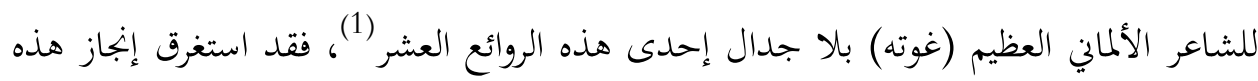

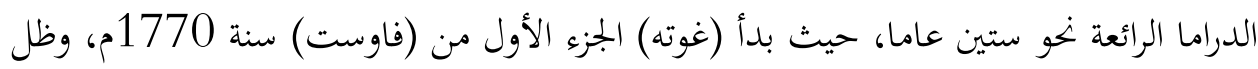

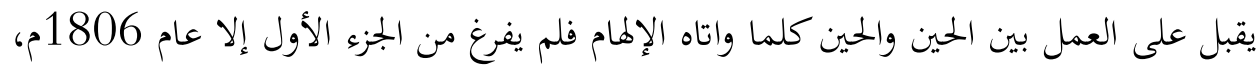

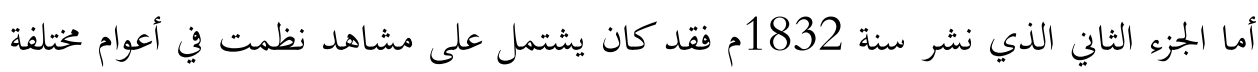

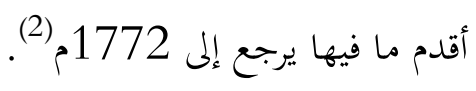

نجد كثيرا من الأعمال المسرحية اتخذت من أسطورة (فاوست) مادة لها، والأصل في هذه الأسطورة غامض بعض الشيء، وإن كانت الآراء تميل إلى أن أساسها أسطورة شعبية

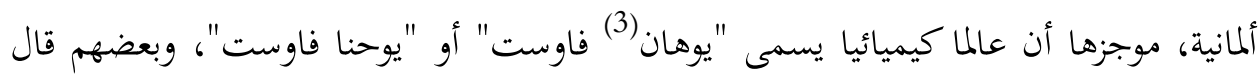
إن اسمه "جورج سابيكوس"، ولد هذا العالم في أواخر القرن الخامس عشر، وكان سكيراً كسولا

1- المسرح العالمي (من اسخيلوس إلى آرثريللر)، لويس عوض، دار المعارف مصر 1964م، ص211.

$$
\text { 2- المرجع السابق، ص211 المسرحي (من المخيلوس }
$$

3- الآداب المقارنة، مُحمّمَ التنوخي، دار الجيل، بيروت، ط1، 11995م، ص119. 
يجيا حياة غامضة عجيبة تتخللها قصص مغربة في الخيال، عدها الكتاب مادة مغرية للكتابة عنها ومعالجتها، وعلى الرغم من وجود (فاوست) تاريخيا فقد حاكت الأساطير الشعبية حوله كثيرا من القصص فزعمت أنه كانت له قرابة مع الشيطان، وأنه كان ساحرا وله قدرة على مخاطبة الموتى وقد وقّع بدمه عقدا مع الشيطان على أن يطيعه في مقابل أن يرجع له الشيطان

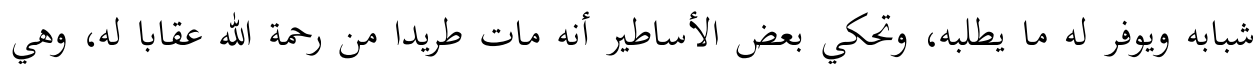

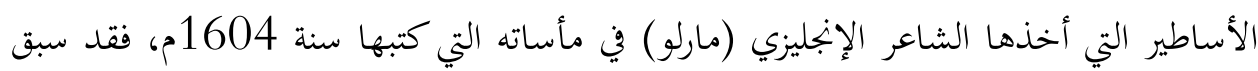

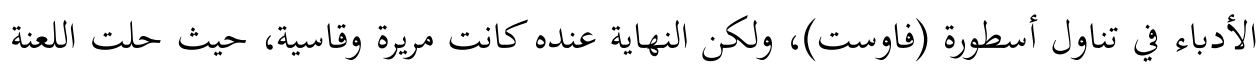
على (فاوست) لمخالفاته في حين تعكس أسطورة أخرى هذا الرأي قائلة إنما باع روحه للشيطان

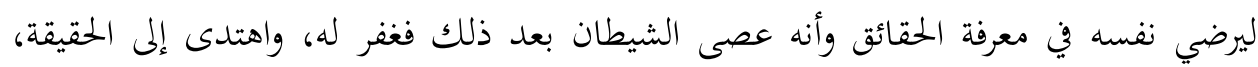
وهذه هي فكرة (غوته) في مسرحيته وبفضل (غوته) صارت شخصية (فاوست) عالمية،

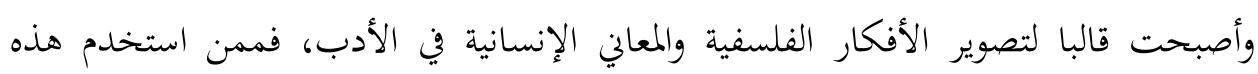
الشخصية "بول فاليري" وتوماس مان" (1).

ومن تم فقد كانت شخصية (فاوست) قبل أن تتحول إلى أسطورة شخصية حقيقية لها وجود في التاريخ وأن صاحبها قد خالف الكتاب المقدس ومارس السحر علانية حتى كانت فايته سنة 1543م في فندق بقرية من قرى "دوقية فورتمبرج"، فقد ورد أن صاحب الفندق سأله

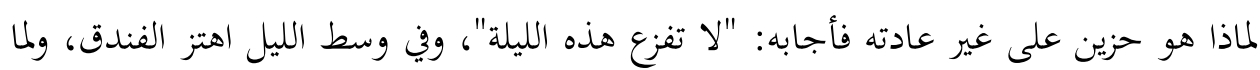

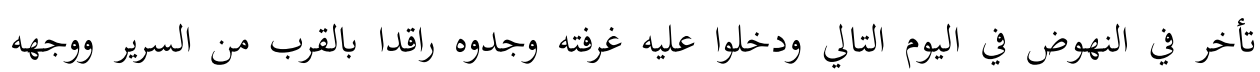
ملتفت إلى ظهره، وعلى هذا النحو قتله الشطيان(2). وقد مرت شخصية (فاوست) قبل أن تتحول إلى أسطورة بثلاث مراحل: 1- مرحلة اختلط فيها التاريخ بالأكاذيب، فرويت عنه أفعال كثيرة تنقصها الدقة ولا تعززها البراهين.

1- الأدب المقارن، مُجمّ غنيمي هلال، دار الثقافة بيروت لبنان، ط5، 1953م، ص318.

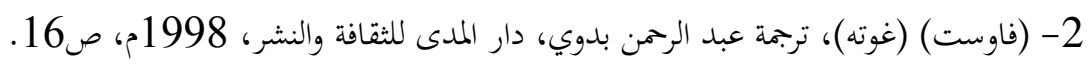


2- بدأت أسطورة (فاوست) وهو لا يزال حيا حيث تناقل الناس أخباره في أسمارهم وأوقات فراغهم، فألفوا عن أفعاله وسلوكه روايات عجيبة، ونسج الخيال حوله كثيرا من العجائب كانوا يقدموها على أفها مواد مسلية لا على أغها معلومات صحيحة. 3- ويف المرحلة الثالثة انتقلت الأسطورة من الشفاه إلى سجلات الكتب (1). وفي الأعمال التي تناولت شخصية (فاوست) كان هو نموذج الإنسان الساعي إلى مزيد من القوة أو الكمال بوسائل خارجة عن الطبيعة هي ما يعرف بالسحر، فالمستقبل مجهول والإنسان يريد معرفة ما سيجيئ، والقوى الطبيعية قاصرة، فعليه إذا أن يبحث عن أشياء خارجة عن الطبيعة وعن قوى خارقة يسخرها لتوفير ما يصبو إليه(2). غير أن (فاوست) (غوته) تمثل قمة توازنه وخصوبته وصفائه، فهي ملحمة كتبت

بالحوار الذي يدعو إلى التأمل والتفكير (3).

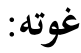

ولد الشاعر الألماني (غوته) (أو جيتته كما ينطقه كثيرون) في صيف 1749م في مدينة فرنكفورت بألمانيا، ونشأ نشأة راقية إذ كان أبوه من أعيان البلدة ومثقفيها، فبرز عند (غوته) ميل إلى النظم والمحاولات المسرحية منذ كان يافعا، وزاد من ذلك تعرفه على (يوهان هيردر) الذي كان له الفضل في تغير دفة ريشته نحو البساطة، بعد أن كان متهافتا على الأدب المصنوع والشعر المتكلف، كما وجهه نحو عباقرة الفطرة الأدبية الذين خلد اسمهم، فحثه على دراستهم من أمثال (شكسبي))، وقاده نحو القدماء من الأدباء العرب، فانكب على دراسة ما ترجم لهم

$$
\begin{aligned}
& 1 \text { - (فاوست) (غوته)، ص21. }
\end{aligned}
$$

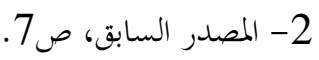

3- المسرح العالمي من أسخيلوس إلى آرثر ميللر، لويس عوض، دار المعارف، مصر، 1964م، ص212. 
إلى الأسبانية واللاتينية والإنجليزية(1)، وقد توفي (غوته) في 22 مارس 1832م، عن ثلاث وتمانين سنة (2) - (2)

وتعد قصة (فاوست) وصفا منطبقا تمام الانطباق على حياة (غوته) الشخصية، فهو الرجل الذي كان طوال عمره باحثا عن معرفة الحقيقة والجمال والخير، كما هو بالضبط في وانياه (فاوست) (3) (3)

قصة (فاوست) ملحمة تمثل صراع الإنسان مع قوى الخير والشر في هذا الوجود سواء

$$
\text { أكانت خارج النفس أم داخلها. }
$$

إخا قصة الإنسان الذي تضيق نفسه الرحيبة بكل ما في الأرض من علم محدود وقوى محدودة ومتعة محدودة، وتطلب نفسه الانطلاق من هذا العالم المحدود واقتحام ذلك العالم المغلق الرهيب الذي حرمته السماء على البشر سعيا وراء المعرفة التي تتجاوز العقل، والحرية التي تتجاوز

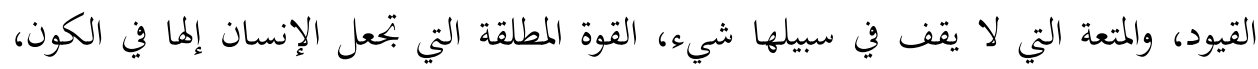
ولكي يحقق الإنسان كل ذلك تراه يحالف الشيطان فيدين له كل شيء في الطبيعة إلى أن يأتي

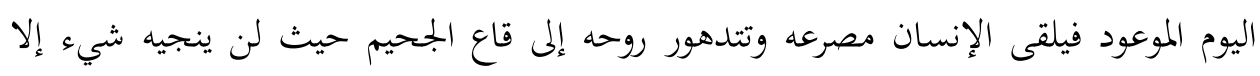
اللطف الإلهي (4). إن هذه القصة ليست من نسج خيال (غوته) وحده، فهي بعض تراث العصور الوسطى، وقد تناولها بعده كثيرون فلم يصل أحد منهم ما وصل إليه هذا الشاعر الفيلسوف الذي صور محنة الإنسان أعظم تصوير (5).

$$
\text { 2- 1 الأدب المقارن، يُحَّمَ التنوخي، ص90. }
$$

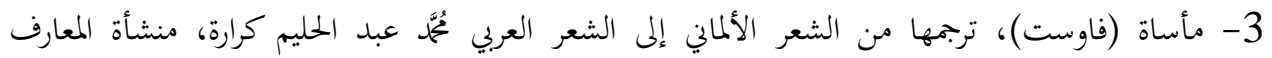

$$
\text { 4- 4- المسرح العالمي، لويس عصدر، 1986م، صأ11. }
$$




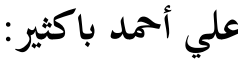

شاعر وكاتب ومسرحي يمني، ولد في مدينة "سوربايا" بأندونيسيا سنة 1900م، من أب يمني وأم أندونيسية، ثم قدم مع والده إلى حضرموت سنة 1910م فتلقى فيها تعليمه الأول، عاد بعدها إلى أندونيسيا وهناك قام بنشاط واسع للتوفيق بين أبناء حضرموت، وفي سنة

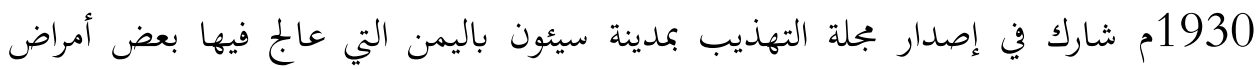

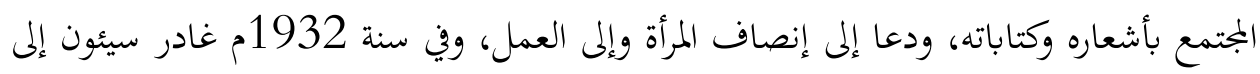
عدن فالصومال فأثيوبيا، ثم وصل إلى الحجاز، وفي مدينة الطائف كتب مسرحيته الأولى "همام وعاصمة الأحقاف"، وفي سنة 1934م رحل إلى مصر حيث التحق بقسم اللغة الإنجليزية

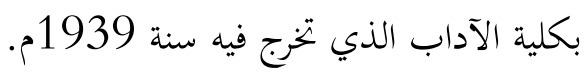
نال (علي أحمد باكثير) جائزة الدولة التشجيعية في الأدب عام 1963مجام، وكان عضو لجنة الشعر في المجلس الأعلى لرعاية الفنون والآداب، له أعمال أدبية متنوعة كثيرة منها:

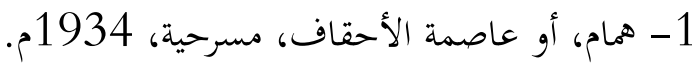

2- سلامة القس، رواية، 1944م.

3- الفرعون الموعود، مسرحية، 1945م، موايه،

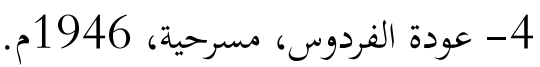

5- سر الحاكم بأمر الله، مسرحية، 1946م.

6- مأساة أوديب، مسرحية، 1949م.

7- الثائر الأحمر، رواية، 1949م.

8- شهرزاد، مسرحية، 1953م.

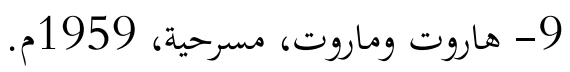

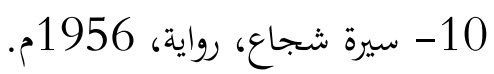

11 - شيلوك الجديد، مسرحية. 


$$
\text { 12 - قصر الهودج، مسرحية(1) }
$$

ومن الكتب الأخرى: فن المسرحية من خلال بتحاربي الشخصية، وأبطال اليرموك، ومن فوق سبع سماوات، كما أن له ديوان شعر بعنوان "أزهار في شعر الصبا".

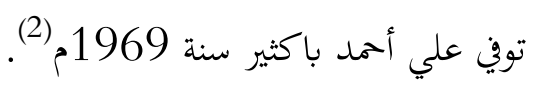

لقد أطل (علي أحمد باكثير) على الآداب الأوربية وعرفها و تأثر بها، لكن شخصيته العربية الإسلامية لم تذب وسط هذا التأثر فاستطاع أن يحافظ عليها وأن يهضم ما اطلع عليه ثم يصوغه في قالب جديد وروح جديدة تخدم أهداف أمته فكانت مسرحياته التي كتبها هادفة نحو تثقيف الذات العبية، ودفعها للتطور والإنماء، ومحاربة أعدائها، فمثلا كانت مسرحيته "مسمار

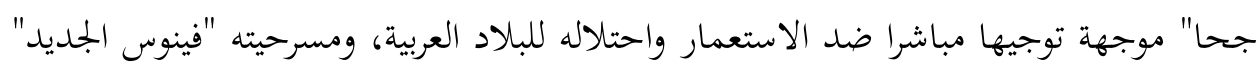

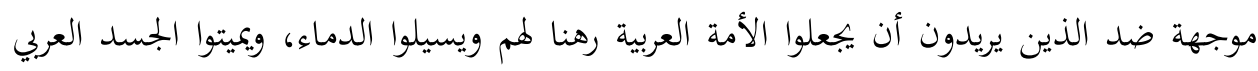
وقد أخذ هذه الفكرة من فكرة شيلوك في مسرحية تاجر البندقية لـ(شكسبير) وطورها لتعني ئنسي الاحتلال الاستيطاني الصهيوني الذي لا يمكن استقراره إلا بالقضاء على مقومات الأمة العربية وإسالة دمائها (3). وفي مسرحية (فاوست) الجديد كان تأثره بـ(غوته) واضحا، ولكنه لم يكن تكرارا لشخصية (غوته) في هذا العمل فقد استوعبه وتمثله وأعاد تشكيله وأفضى به إلى نتيجة يرضاها، إذ وصل في فاية المسرحية إلى انتصاره على الشيطان وكسبه للرهان الذي كان بينهما، وفيها حارب الفكر الخرافي المتعاون مع الشر، والمثبط للهمم، والحائل دون تقدم الأمة، الذي يسعى إلى إغراقها في الملذات والشهوات، ويصرفها عن التطور والابتكار والبحث العلمي الهادف (4).

1- معجم الروائيين العرب، سمير روحي الفيصل، ط1، 1995م-1415هـ، جروس بيرس، لبنان، ص294.

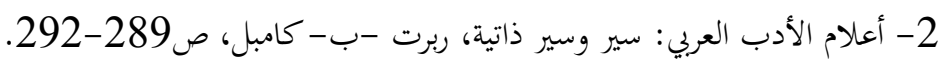

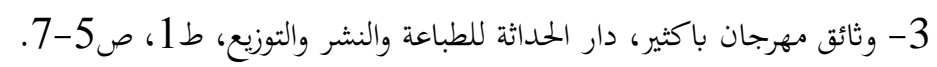

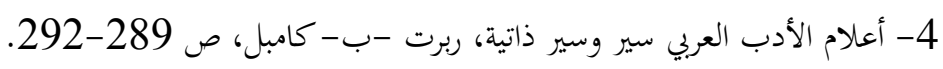




\section{ما بين العملين من تقارب واختلاف:}

بالمقارنة بين عمل (باكثير) وعمل (غوته) نلحظ أن (باكثير) قد اتكأ على عمل (غوته) اتكاء كاملا، حتى أصبح بإمكاننا أن نقول إنه لولا عمل (غوته) ما وجد إنه عمل (باكثير)، وأن السابق سبب في اللاحق وعلة له، وتأثر (باكثير) ب(غوته) كان عن وعي تام

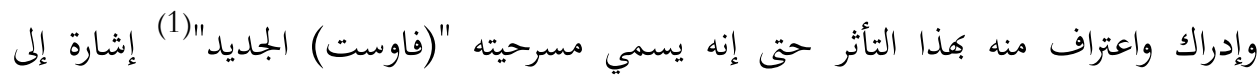
(فاوست) الأول الذي كان مصدرا له في هذا العمل، غير أن مسرحية (باكثير) جاءت متشربة بالروح الإسلامية مع مراعاة الزمان والمكان في شخصيات المسرحية الأصلية، ففي مسرحية

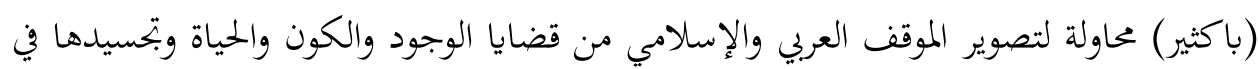
عمل أدبي يجعل من أسطورة معروفة موضوعه، بجيث لا تصعب على أبناء الأمم الأخرى ممن

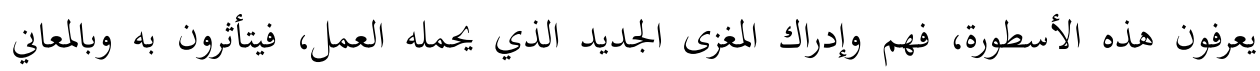
الجديدة التي يمملها.

وينفرد (باكثير) برؤية مهمة تدل على سعة أفقه حين يعطي للأدب العربي بعدا عالميا،

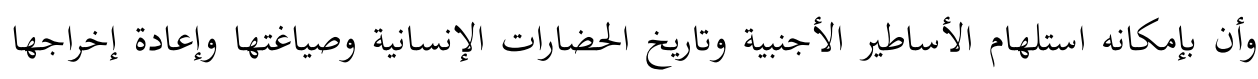

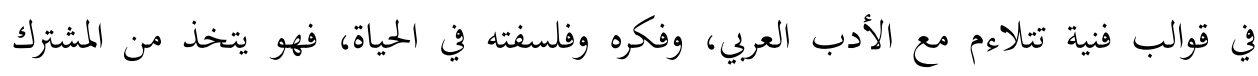
الإنساني جسرا لإيصال ما يريد إيصاله بسهولة وبيسر.

يبدأ (باكثير) مسرحيته من حيث بدأ (غوته)، فهما متفقان في صورة المكان والحالة

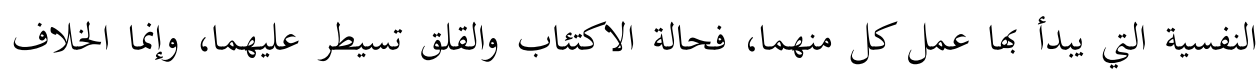
بينهما في سبب هذا الاكتئاب والقلق ومبعثه، فهو عند (غوته) ناتج عن عدم اقتناعه بالعلوم

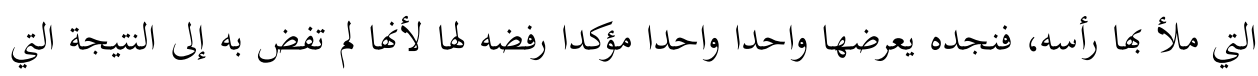

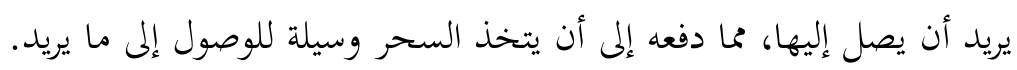

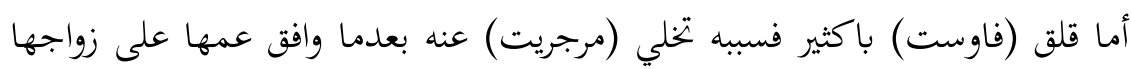
منه، وذلك أن (فاوست) أخبرها بأنه اكتشف طريقة يمكنه بها تحويل المعادن إلى ذهب، وأنه

1- (فاوست) الجديد، علي أحمد باكثير، مسرحية في أربعة فصول، "د.ط". 
زيف النقود، فلحقت (مرجريت) بالدير وتركته، فعد (فاوست) هذا العمل خيانة له، وقرر أن ينتحر، ولكن ظهور الروح "بارسيل" أقنعه بالتخلي عن هذا القرار، وأنه لا توجد امرأة تستحق

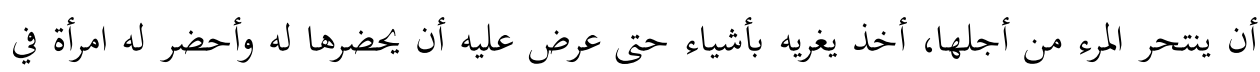
صورةا، وبذلك تخلى عن قراره. إن القضية العامة لمسرحية (فاوست) عند (غوته) هي التردد بين العقل والقلب، ومن أول المسرحية نرى (فاوست) شقيا بعقله ولم يستطع به أن يدرك طعم السعادة، ولا أن يذوق

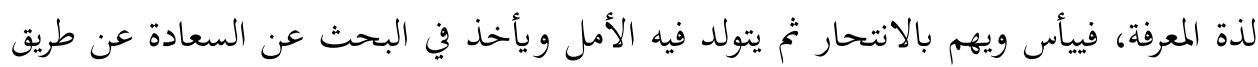
إغناء مشاعره والانغماس في بتحارب حيوية مختلفة الأنواع يصاحبه فيها روح الشر "مافيستوفيليس"، ويأتي (فاوست) بآثام يعتريه فيها الندم، ويكون هذا الندم تكفيرا عن سيئاته، وعلامة على روح الخير فيه، ويظل في هذه الآثام طوال الجزء الأول من المسرحية، وهو الجزء الذي ينتهي بنجاة (مرجريت) منه ومن روح الشر. وفي الجزء الثاني يظل (فاوست) منغمسا في بتحارب الحياة، ويهتدي بها إلى أن الحقيقة المجردة فوق قدرة العقل المجرد، ويتعرف على "هيلين" رمز الجمال الخالص، فيهتدي عن طريقها إلى الخير، وهو غاية ما يستطيع المرء الوصول إليه بعواطفه الإنسانية وروحه الصافية، فقضية

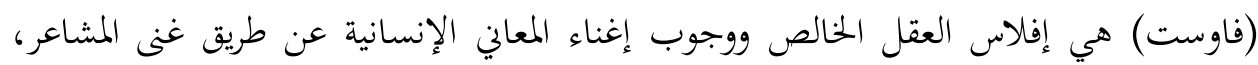

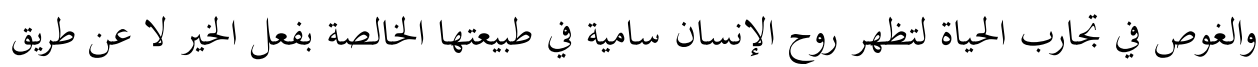
البقاء في نطاق التفكير المجرد(1). والقضية تكاد تكون نفسها عند باكثير، فهو يبدو مكتئبا حزينا قد مل الحياة والبقاء

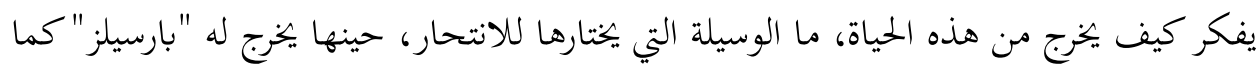

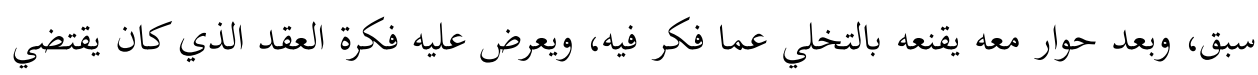

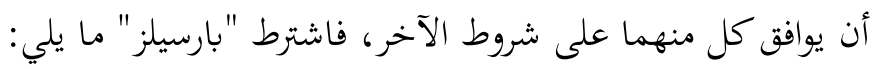
1- أن يقبل الروح كل ما يطلبه منه (فاوست).

1- الأدب المقارن، مُحَّم غنيمي هلال، ص292. 
2- أن يكون مطيعا له يخدمه وينفذ كل ما يكلفه به. 3- أن يَّْضر له كلما دعاه ويضع نفسه تحت تصرفه. فوافق واشترط على (فاوست) ما يلي: 1- يعد (فاوست) ويقسم أنه صار مِلكا للروح. 2- وتوكيدا لهذا العهد على (فاوست) أن يصادق على ذلك بلدماته. 3- أن يكون (فاوست) عدوا للأديان، وأن يكفر بها ولا يعود إليها لـان. فالمسرحيتان تتفقان في: 1- مناجاة (فاوست) ووصف حالته 2- ظهور الروح. 3- تبادل المشاهد وتلبية المطالب وتوفير المغريات.

$$
\text { 4- الإعلان عن غاية (فاوست). }
$$

وتتفق المسرحيتان كذلك في العهد المبرم، وفي كتابته، والتصديق عليه بدم (فاوست)، وفي تحديد مدته بأربع وعشرين سنة، ولعل نقطة الاختلاف هنا أن (باكثير) قد جعل في هذه المعاهدة شاهدا على ما وقع بين (فاوست) و(بارسيلز)، وهو الله سبحانه وتعالى، بينما المعاهدة في (فاوست غوته) خالية من الشهود. ومما يلحظ في العملين اختلاف الشكل الذي كانت عليه هاية (فاوست)، فنهايته في (فاوست غوته) كانت بموته موتا طبيعيا، عندما طلب أن تتوقف اللحظة التي أحس فيها بغاية الجمال ومنتهى السعادة، فهو يقول: (( ...لا يستحق الحرية والسعادة إلا من يسعى كل يوم للظفر بهما، هكذا يمضي الطفل والرجل والشيخ العجوز هنا أعمارهم في بلاد حسنة محاطين

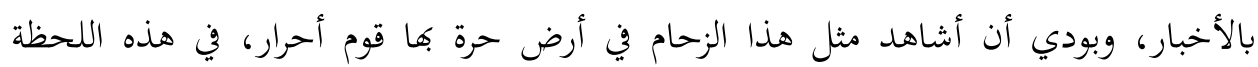
سيكون من حقي أن أقول: "توقفي إذا فأنت في غاية الجمال )(2)، وهنا يموت (فاوست).

$$
\begin{aligned}
& \text { 1- (فاوست) (غوته)، ص25-26. }
\end{aligned}
$$

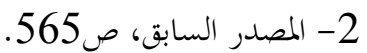


أما في مسرحية (باكثير) فقد كانت فاية (فاوست) على يد "بارسيلز"(1) حيث طعنه بخنجر مسموم كان يخفيه، حرصا منه على أن يحصل على نتائج الأبحاث والدراسات التي كان (فاوست) يجريها طوال حياته، ولم يكن بارسيلز يعلم أن (فاوست) قد أحرقها، لأنه يعلم بأها لو وقعت في يد أعداء الإنسانية فسوف تستخدم لاستعباد الناس والتحكم فيهم، ومن أثر هذه الطعنة مات (فاوست) باكثير.

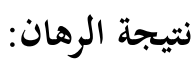

اختلفت آراء الدرسين والباحثين في تعيين من الذي كسب الرهان، ففي مسرحية (باكثير) نجد أن الذي كسب الرهان هو (فاوست) دون شك إذ تمكن من أن يخلص نفسه ويسترد روحه من الشيطان ويجعلها ملكا لله وحده، بعدما نقض "بارسيلز" العقد الذي أبرمه معه بتقصيره في الإيفاء بما طلبه منه، وكان هذا من ضمن شروط العقد. وأما في مسرحية (غوته) فنجد معرفة الذي كسب الرهان مشكلة شائكة شغلت الباحثين، وقد ذكر عبد الرحمن بدوي في تقديمه للمسرحية أن "أدام كلت" عرضت آراء أربعة وأربعين باحثا في هذا الموضوع، وانتهت إلى أن واحدا وعشرين باحثا قالوا إن (فاوست) كسب الرهان، وأن عشرة أكدوا من حيث المعنى الحريف أنه خسر الرهان، لكنه على مستوى أقل كسبه، وأن ثلاثة عشر باحثا رأوا أن (فاوست) قد خسر الرهان(2).

$$
\text { 2-1 (فاوست) الجديد، علي أحمد باكثير، ص79. }
$$




\section{المصادر والمراجع}

1- الآداب المقارنة، يُحَّم التنوخي، دار الجيل بيروت، ط: 1، 1995م.

2- الأدب المقارن، ب، فان تيجيم، تعريب سالم مفتاح الحسامي، منشورات المكتبة العصرية، صيدا-بيروت.

3- الأدب المقارن أصوله وتطوره ومناهجه، الطاهر أحمد مكي، دار المعارف، القاهرة، ط: 1،

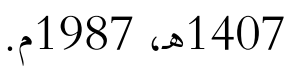

4- الأدب المقارن، عُمَّم غنيمي هلال، دار الثقافة بيروت لبنان، ط: 5، 1953م. 1953. 5- أعلام الأدب العربي سير وسير ذاتية، روبرت -بعابـ كامبل الياسوعي، الشركة المتحدة لـتوزيع، ط: 1، 1996م. 1996. 6- دراسات في الأدب المقارن، بديع يُعَّم جمعة، دار النهضة العربية، بيروت، ط: 2، 1980

7- (فاوست) الجديد، علي أحمد باكثير، مسرحية في أربعة فصول، الناشر مكتبة مصر.

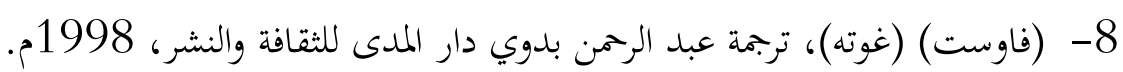

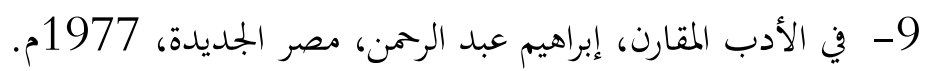

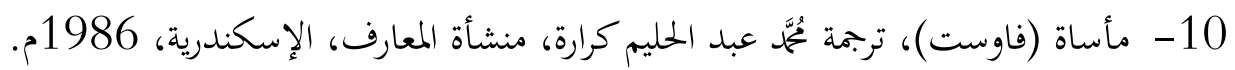

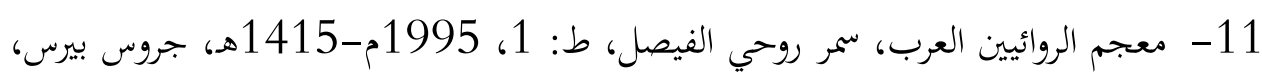
لبنان.

12- المسرح العالمي (من أسخيلوس إلى آرثريللر)، لويس عوض، دار المعارف مصر، 1964 13- هضة الأدب المقارن، مقالة للكاتب انيامبل، نشرها في مجلة الكاتب المصري، المجلد السابع عشر، العدد: 28، دار الكتاب المصري، القاهرة، العدد: 28، يناير، 1948م، ونقلها عن الفرنسية مصطفى كامل فودة. 14- وثائق مهرجان باكثير، دار الحداثة للطباعة والنشر والتوزيع، ط: 1، همب، 1968م. 